\title{
LOPES, José Rogerio. 2017. Colecionismo, arquivos pessoais e memórias patrimoniais
}

\section{Nádia Philippsen Fürbringer}

\section{(2) OpenEdition \\ 1 Journals}

Edição electrónica

URL: http://journals.openedition.org/aa/3554

DOI: $10.4000 / a a .3554$

ISSN: 2357-738X

Editora

Programa de Pós-Graduação em Antropologia Social (UnB)

\section{Edição impressa}

Data de publição: 1 junho 2019

Paginação: 349-353

ISSN: 0102-4302

\section{Refêrencia eletrónica}

Nádia Philippsen Fürbringer, «LOPES, José Rogerio. 2017. Colecionismo, arquivos pessoais e memórias patrimoniais», Anuário Antropológico [Online], v.44 n.1 | 2019, posto online no dia 06 julho 2019, consultado o 28 abril 2021. URL: http://journals.openedition.org/aa/3554 ; DOI: https://doi.org/ 10.4000/aa.3554

\section{(c) (i) (9)}

Anuário Antropológico is licensed under a Creative Commons Atribuição-Uso Não-Comercial-Proibição de realização de Obras Derivadas 4.0 International. 


\title{
LOPES, José Rogerio. 2017. Colecionismo, arquivos pessoais e memórias patrimoniais. Porto Alegre: CirKula. 151p.
}

\author{
Nádia Philippsen Fürbringer \\ Universidade Federal de Santa Catarina - Brasil
}

A prática do colecionismo como um fenômeno social é o tema do livro do professor e pesquisador José Rogério Lopes, que lança um olhar cuidadoso sobre arquivos pessoais e memórias patrimoniais enquanto frutos de interações sociais. O livro é resultado de uma longa trajetória de pesquisa acerca do tema, que se iniciou com um projeto financiado pelo CNPq e realizado entre 2012 e 2014, um vídeo-documentário e outras publicações posteriores. As pesquisas foram realizadas em estâncias turísticas ou que possuem sítios histórico-patrimoniais nos estados do Rio Grande do Sul, São Paulo, Minas Gerais e Pará. Lançado em 2017, o livro tem 151 páginas e se inicia com a Apresentação contextualizando a obra, três capítulos de discussão teórica e com dados de campo e um Encerramento descrito como provisório ao indicar futuros encaminhamentos da pesquisa.

"Por que as pessoas colecionam coisas?" é a pergunta que orienta o primeiro capítulo do livro. A prática do colecionismo é apresentada por um quadro explicativo que associa tal prática social às representações dos ciclos de vida. Seguindo teóricos clássicos como Durkheim, Bataille, Sahlins, Simmel, Halbwachs, entre outros, o autor defende o caráter universal do ato de colecionar, demonstrando que tais práticas são orientadas por princípios e valores definidos socialmente. Mas seu empenho argumentativo se coloca na demonstração das fases de desenvolvimento psíquico da criança e seu engajamento com determinados objetos, iniciando a formação das coleções, que ganham mais volume na adolescência, mas que na entrada na vida adulta podem não interessar mais. $\mathrm{O}$ autor salienta que essa perspectiva é percorrida para compreender a ideia de self que considera central para o entendimento dessa prática. A constituição da identidade em si, permeada pela interação social através da aceitação grupal e coletiva, é uma identidade na ação em que o eu e o outro são construídos. Portanto, as coleções e suas práticas são concebidas como a relação entre ciclos de vida e as percepções condicionadas nos vínculos que o indivíduo estabelece com o outro. Os objetos colecionados, desse modo, estabelecem o reconhecimento entre os indivíduos, mediando significativamente as relações.

O segundo capítulo se constitui de elementos que compõem o quadro expli- 
cativo sobre as motivações e propósitos dos colecionadores. Lopes apresenta três casos das interações em torno de coleções particulares e seus colecionadores. São três homens: um de São Paulo que coleciona girafas em diversas formas e dois do Rio Grande do Sul, um com uma coleção de chaveiros e outro com fotografias e recortes de jornal. O sentido atribuído em tais coleções vai além da dimensão cognitiva do indivíduo colecionador, como exposto no capítulo anterior, ao apresentar novas significações, pela incorporação de outras referências e pelo amadurecimento do seu proprietário. São diferentes formas como os colecionadores interagem com a ordem material da cultura - podem ser expostas, na própria casa do colecionador ou em um espaço aberto ao público, mas podem também permanecer guardadas em gavetas e no fundo de um armário.

Uma das contribuições principais que a obra traz para o campo da Antropologia é a reflexão sobre a prática do colecionismo não centrada na biografia social das coisas ou na biografia individual do colecionador. Estas perspectivas já têm um campo sedimentado nas discussões de Kopytoff (2008) e Appadurai (2008), por exemplo. A visão almejada pelo autor ao analisar as presenças e ausências na prática do colecionismo é uma proposta reflexiva acerca de como se estabelece essa relação do self com a cultura material, compreendendo a implicação da ordem material na produção de sociabilidades.

As coleções são compreendidas por Lopes como formações culturais materiais, resultados de projeções de atributos individuais, ressignificadas em processos de reconhecimento que permitem mediações significativas com os indivíduos. $\mathrm{O}$ ato de colecionar é, portanto, considerado como um ato comunicacional, através do ordenamento dos objetos e sua organização se faz como discurso. Não se trata somente da permanência enquanto preservação do objeto que compõe a coleção, mas também da ausência. Essa duplicidade, proposta por Aumont (1995) acerca das imagens, é estendida na conceitualização da coleção, constitui a formação sensível do pensamento, pela presença de objetos visualizada e sentida igualmente através da ausência na composição da coleção.

Por fim, para atingir essa proposta como um todo, o autor avança na discussão de como os “contratos de visibilidade” também compõem esse quadro reflexivo. Apresenta três narrativas artísticas que são compostas por enredos que descrevem a relação entre indivíduos, seus selfies, e seus papéis, como colecionadores, nas relações com outros. A argumentação segue demonstrando como os quadros de experiência colecionista evidenciam sua constituição enquanto redes de sociabilidade que 
dão o suporte à formação dos colecionadores e também aos seus aprendizados. $\mathrm{Ou}$ seja, as coleções possuem marcações individuais de um ciclo de vida, ou de passagem desses ciclos, mas podem se constituir em marcações coletivas, que, inclusive, podem adquirir também valor de mercado.

O terceiro capítulo introduz um debate mais conhecido no campo da Antropologia, que é a singularização das coleções. As coleções estão sujeitas aos diversos fluxos que atravessam os vínculos que os indivíduos engajam nas coisas (mercantilização, troca, consumo e produção de valores sociais) e que as definem como bens sociais e patrimônios. Assim, a proposta do autor é argumentar que "a valoração patrimonial de coisas e pessoas se constitui por diferentes níveis de interação, nos interstícios da relação entre bens sociais e memórias individuais e coletivas" (:91). Debate já empreendido por Appadurai (2008), mas que na visão de Lopes, é possível transcender as fronteiras da localidade. Para avançar, Lopes argumenta que a memória deve ser compreendida como vetor de difusão de valores dos bens sociais. O valor de um bem se consolida a partir da memória coletiva, e a interação dos colecionadores pode ser compreendida como procedimentos rituais. Isso atestaria o deslocamento do local para o coletivo. Articular as noções de tempo e memória desenha o campo do self em contraposição ao outro e ao coletivo, essenciais para pensar as representações da vida individual e coletiva, defendendo o lugar da memória para a definição de acontecimentos que registram a ordem de aquisição dos bens. Assim também é possível vislumbrar os valores intrínsecos à disponibilidade pessoal ou coletiva dos bens.

Lopes também mapeia as discussões acadêmicas acerca das coleções, olhando mais atentamente para casos de diversidade cultural e patrimônio. Destaca a emergência de novas concepções de coleções contemporâneas, propostas por Canclini (1990). Assim, a partir desse mapeamento, apresenta os dados etnográficos de forma mais aprofundada, através da descrição de três quadros de experiências colecionistas. Primeiro, há um colecionador de São Luiz do Paraitinga/SP, que guardava imagens da indústria cultural vinculadas ao contexto histórico da sua cidade. $\mathrm{O}$ segundo colecionador era de Canela/RS e colecionava camisas de futebol. Por fim, um colecionador de fotografias antigas da sua cidade, Mariana/MG. Importante identificar que duas das coleções abordam, de alguma forma, imagens históricas das cidades (Canela e Mariana), ponto bastante trabalhado pelo autor. Questiona-se se tais práticas e agenciamentos colecionistas reverberam de forma semelhante em coleções propostas por mulheres. Há, no início do livro, um exemplo de uma 
senhora britânica e sua coleção, mas para o cenário brasileiro, seria interessante se mais quadros de experiências colecionistas de mulheres fossem aprofundadas.

Ao descrever esses quadros, Lopes adentra a discussão dos Arquivos Pessoais, somando a sua análise a de Heymann (2009), uma das poucas intelectuais que se dedica ao tema dentro da Antropologia brasileira. O autor considera os processos de agenciamento que os indivíduos operam sobre suas coleções, através dos diversos repertórios sobre práticas e processos de patrimonialização, atento também aos processos de singularização e produção do mercado que pautam a relação entre as pessoas e os objetos. Especialmente quando se têm em vista as ações de exposição dessas coleções pelos seus colecionadores, mostrando o deslocamento de um registro individual, que as originaram, transformando-as em registros coletivos, que as mantêm, tornando-se bens de marcação simbólica.

Para Lopes, é importante compreender a "disponibilidade que se projeta dos indivíduos, em exteriorizar seus objetos de coleção num campo de negociação de memórias, mesmo quando tal campo é concebido como um jogo de características maleáveis" (:138). Ele finaliza apresentando caminhos para o campo de pesquisa sobre coleções, através de abordagens focadas na cultura material, na relação entre humanos e não humanos e também em outros campos científicos como, por exemplo, a psicanálise. Os estudos acerca das coleções, das memórias patrimoniais e dos arquivos pessoais seguem seu próprio objeto, não se esgotam e sugerem mais possibilidades de pesquisa.

Recebido: 01/10/2018

Aprovado: 25/01/2019

Nádia Philippsen Fürbringer é doutoranda no Programa de Pós-Graduação em Antropologia Social da Universidade Federal de Santa Catarina. Sua pesquisa tem financiamento da agência CAPES. Atua como pesquisadora do Grupo de Pesquisa $\mathrm{CNPq}$ Coletivo de Estudos em Ambientes, Percepções e Práticas - CANOA/ UFSC. ORCID: 0000-0003-0281-4967. Contato: nadiapf@gmail.com 


\section{Referências Bibliográficas}

AUMONT, Jacques. 1995. A imagem. Campinas: Papirus.

APPADURAI, Arjun. 2008. "Introdução: mercadorias e a política de valor". In: A vida social das coisas: as mercadorias sob uma perspectiva cultural. Rio de Janeiro: EdUFF. p. 15-87.

HEYMANN, Luciana Quillet. 2009. Estratégias de legitimação e institucionalização de patrimônios históricos e culturais: o lugar dos documentos. Texto apresentado na VIII Reunião de Antropologia do Mercosul, Buenos Aires.

KOPYTOFF, Igor. 2008. “A biografia cultural das coisas”. In: APPADURAI, Arjun. A vida social das coisas: as mercadorias sob uma perspectiva cultural. Rio de Janeiro: EdUFF. p. 89-121. 